\title{
Sunlight-Induced Reduction of Ionic Ag and Au to Metallic Nanoparticles by Dissolved Organic Matter
}

\author{
Yongguang Yin, Jingfu Liu, ${ }^{*}$ and Guibin Jiang \\ State Key Laboratory of Environmental Chemistry and Ecotoxicology, Research Center for Eco-Environmental Sciences, Chinese Academy of Sciences, Beijing 100085, China
}

M etal-engineered nanoparticles (MENPs) with unique optical, electronic, and chemical properties have potential applications in catalysis, optical devices, and electronic applications. ${ }^{1}$ Particularly, metallic silver nanoparticles (AgNPs) have been applied as a broadspectrum antimicrobial agent in recent years. Colloidal nanosilver has been used for more than 100 years and has been registered as a biocidal material in the U.S. since $1954 .^{2}$ AgNPs are the most common materials in nanotechnology-based consumer products, and the worldwide production of AgNPs was estimated at $500 \mathrm{t} / \mathrm{a}$ in 2008. ${ }^{3}$ Inevitably, these MENPs can be discharged into the environment through the manufacturing, usage, disposal, and recycling processes of commercial products. ${ }^{4-7}$ The potential toxicity ${ }^{8}$ and bioaccumulation $^{9-11}$ of MENPs such as gold nanoparticles (AuNPs) and AgNPs make it necessary to probe their fates and behaviors in the environment, including transport, aggregation, dissolution, and other transformation processes.

Besides anthropogenic sources, metal nanoparticles can also form naturally in the environment from larger non-nano-objects ${ }^{12}$ or ions in solution by chemical ${ }^{13}$ or biological ${ }^{14,15}$ reduction. This is evidenced by the observation of AuNPs and AgNPs in ore deposits ${ }^{16,17}$ and environmental waters. ${ }^{18}$ It is believed that these nanoparticles play important roles in geochemical reactions, weathering processes, metal migration, and supergene enrichments. ${ }^{16}$ Although there is high correlation between metal enrichments and organic matters, ${ }^{19}$ the source of AuNPs and AgNPs in the natural environment is still not well understood. Discovering the pathway and mechanism for formations of metal nanoparticles in the natural environment is critical for better understanding the environmental fates of

\section{ABSTRACT}

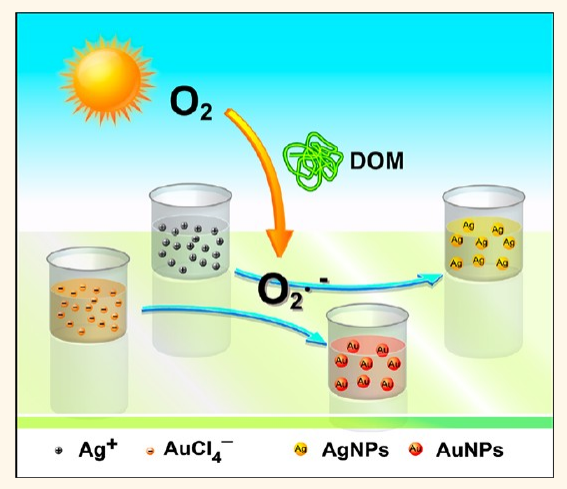

Despite the possible occurrence of metal nanoparticles in the environment due to the discharge of engineered nanoparticles and the natural transformation of metal ions into metal nanoparticles, little is known about the transformation mechanism, fates, behaviors, and effects of these nanoparticles in the environment. Here, we show that dissolved organic matter (DOM) in environmental waters can mediate the reduction of ionic Ag and Au to their metallic nanoparticles under natural sunlight, suggesting that this process may be general for metals with high reduction potential. We demonstrated that the reduction was mediated by superoxide from photoirradiation of the phenol group in DOM, and the dissolved $\mathrm{O}_{2}$ significantly enhanced the formation of Ag nanoparticles. These results imply that previous knowledge about $\mathrm{O}_{2}$-induced dissolution and its effect on persistence of $\mathrm{Ag}$ nanoparticles should be reconsidered in a sunlit DOM-rich aqueous environment. This study can also shed light on understanding possible natural sources of $\mathrm{Ag}$ and $\mathrm{Au}$ nanoparticles in the aquatic environment, which is possibly critical in the supergene enrichment of $\mathrm{Ag}$ and $\mathrm{Au}$.

KEYWORDS: silver nanoparticles · gold nanoparticles · naturally occurring nanoparticles $\cdot$ reduction $\cdot$ dissolved organic matter $\cdot$ superoxide

MENPs and also the biogeochemical cycles of important metal elements, such as $\mathrm{Au}$, $\mathrm{Ag}$, and $\mathrm{Cu}$.

Dissolved organic matter (DOM) is a polydispersed mixture of natural high molecular weight polymer macromolecules derived from the debris of organisms and is ubiquitous in aquatic ecosystems. Although chemical characteristics of DOM are still not well understood, the fate, mobility, transformation, and bioavailability of natural and *Address correspondence to
jfliu@rcees.ac.cn.

Received for review May 23, 2012 and accepted July 22, 2012.

Published online July 22, 2012 10.1021/nn302293r

() 2012 American Chemical Society 

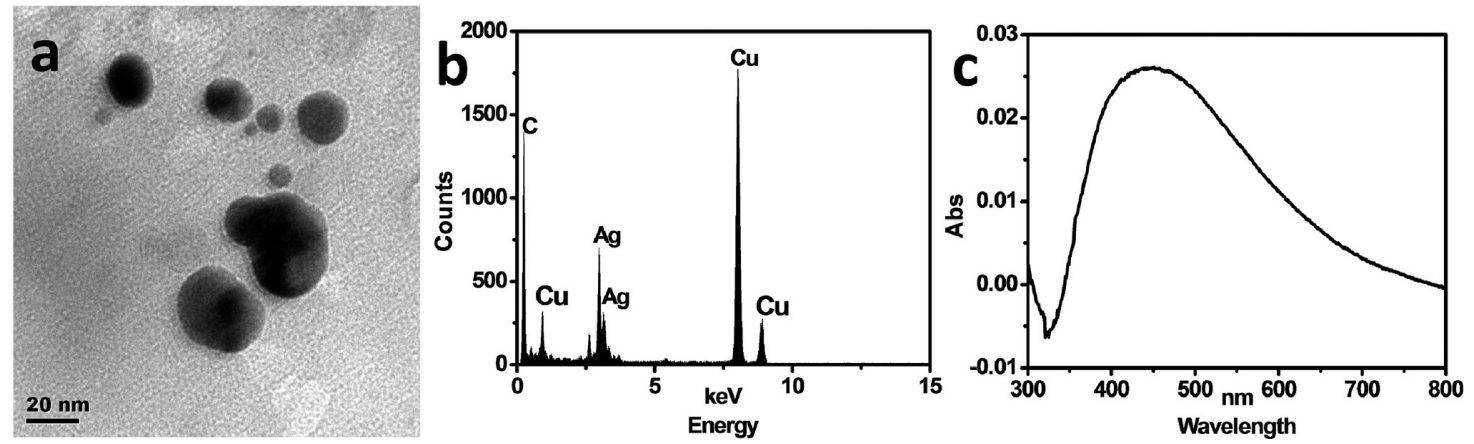

Figure 1. Identification of AgNPs produced by the reduction of $0.01 \mathrm{mmol} \mathrm{L}^{-1} \mathrm{AgClO}_{4}$ in Chaobai River water under sunlight. (a) TEM, (b) EDS, and (c) UV-vis spectrum of the formed AgNPs. The cumulative PAR is $10124.51 \mathrm{E} \mathrm{m}^{-2}$. Note, in (c), the background absorption of Chaobai River water was deducted from the prepared AgNP solution.

anthropogenic pollutants is believed to strongly depend on their interaction with DOM. ${ }^{20,21}$ The ability of DOM to mediate and facilitate a wide variety of reduction reactions has been recognized for several decades. ${ }^{20-22}$ In this process, natural sunlight is often a controlling factor influencing the redox kinetics of many metal elements, including $\mathrm{Hg}(\mathrm{II}),{ }^{23} \mathrm{Fe}(\mathrm{III}),{ }^{24} \mathrm{Mn}$ (IV), ${ }^{25}$ and $\mathrm{Cr}(\mathrm{VI}) .{ }^{26}$

Here, we present the direct evidence for the photochemical reduction of ionic $\mathrm{Ag}$ and $\mathrm{Au}$ to metallic nanoparticles by DOM in natural waters under sunlight. Moreover, the formation kinetics and mechanism of AgNPs were further probed by using humic acid (HA) as a model for DOM. These findings are helpful to enrich our knowledge on the environmental fates of engineered nanoparticles of $\mathrm{Ag}$ and $\mathrm{Au}$, as well as the occurrence of naturally occurring AgNPs and AuNPs and their effect on biogeochemical cycles of $\mathrm{Ag}$ and $\mathrm{Au}$.

\section{RESULTS}

Photoreduction of $\mathrm{Ag}^{+}$to AgNPs in Environmental Waters under Sunlight. The formation of AgNPs in environmental water (from Chaobai River, Beijing) was investigated by spiking $0.01 \mathrm{mmol} \mathrm{L}^{-1}\left(\sim 10 \mathrm{mg} \mathrm{L}^{-1}\right.$ as $\left.\mathrm{Ag}\right) \mathrm{AgClO}_{4}$ as a precursor and exposing the mixture to sunlight with a cumulative PAR (photosynthetically active radiation) of $10124.51 \mathrm{E} \mathrm{m}^{-2}$ for $4.0 \mathrm{~h}$. Formation of AgNPs was evidenced through transmission electron microscopy (TEM), energy-dispersive spectroscopy (EDS), and UV-vis spectrum results (Figure 1).

As the characterization of AgNPs at low concentration is challenging, further experiments were performed with higher concentrations of $\mathrm{AgClO}_{4}$ $\left(0.2 \mathrm{mmol} \mathrm{L}^{-1}\right)$ as the precursor. For DOM-rich (9.04$34.18 \mathrm{mg} \mathrm{L}^{-1}$ dissolved organic carbon (DOC)) environmental waters (such as water from Chaobai River, Wenyu River, and Yongding River in Beijing), a wide absorption peak was observed at 400-550 nm (Figure S1a in Supporting Information). The AgNP suspensions were tinted red rather than yellow with absorption at $\sim 550 \mathrm{~nm}$. It is assumed that the wide absorption peak is formed by the overlap of an absorption peak at $400 \mathrm{~nm}$ (surface plasmon resonance (SPR) absorbance of monodisperse AgNPs) ${ }^{27}$ and an absorption peak at higher wavelength (SPR absorbance of stable AgNP agglomerates). ${ }^{27,28}$ This assumption was validated with the observance of $\mathrm{Ag}^{+}$reduction when spiking Suwannee River HA (SRHA) into environmental waters and subsequently exposing the mixture to sunlight (Figure S1b). We found that SRHA, functioning as both a reducing and capping agent, could improve the total AgNP formation and the fraction of dispersed AgNPs. The formation of AgNPs in environmental waters was demonstrated comprehensively by TEM, highresolution TEM (HRTEM), selected area electron diffraction (SAED), EDS, X-ray diffraction (XRD) (Figure 2a-e), and X-ray photoelectron spectroscopy (XPS, Figure S2) analysis. The SAED patterns (Figure 2c) and lattice planes observed in HRTEM imaging (Figure 2b) can be indexed to face-centered cubic (fcc) silver metal. XRD data (Figure 2e) evidence the existence of both $\mathrm{AgCl}$ and AgNPs with the fcc structure matching that of metallic silver. The XPS data (Figure S2) further confirmed the presence of zerovalent silver. The generated AgNPs were stable at room temperature (RT) and $4{ }^{\circ} \mathrm{C}$ in the dark (Figure 2f). However, when these AgNPs were continually exposed to sunlight over $3 \mathrm{~h}$, visible black sedimentation of the formations was observed, and the tint of the solution changed from red to clear.

The UV absorption of AgNPs at $\sim 550 \mathrm{~nm}$ indicated that some portions of the AgNPs were aggregated. We tested the effects of environmental waters on the induced aggregation of AgNPs. After engineered AgNPs (polyvinylpyrrolidone (PVP)-coated AgNPs) were mixed with river water, the absorption peak at $\sim 400 \mathrm{~nm}$ (SPR absorbance of single AgNPs) ${ }^{27}$ decreased significantly, while a new absorption peak appeared at a higher wavelength (SPR absorbance of stable agglomerates) ${ }^{27}$ and the tint of the solution changed from yellow to red. This absorption intensity was observed to increase with time, suggesting increasing amounts of aggregation with continual exposure to river water contents (as shown in Figure S3). 

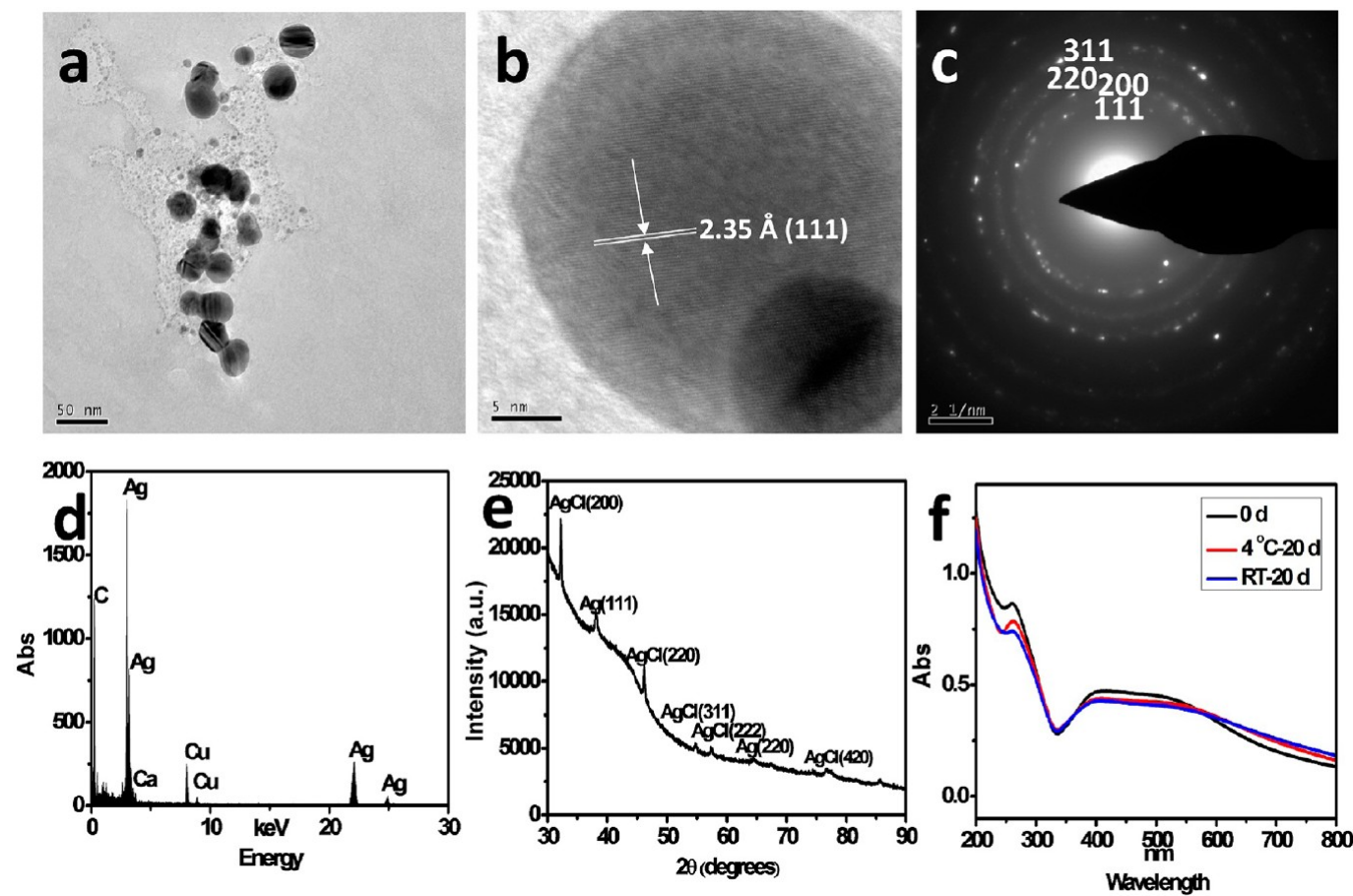

Figure 2. Identification and characterization of AgNPs produced by the reduction of $0.2 \mathrm{mmol} \mathrm{L}^{-1} \mathrm{AgClO}_{4}$ in Chaobai River water under sunlight. The cumulative PAR is $7887.73 \mathrm{E} \mathrm{m}^{-2}$. (a) TEM, (b) HRTEM, (c) SAED, (d) EDS, (e) XRD, and (f) UV-vis spectrum of the formed AgNPs. Note, UV spectrum results suggest the formed AgNPs in environmental water are stable at $4{ }^{\circ} \mathrm{C}$ and $\mathrm{RT}$ in the dark.

Similar behavior has previously been reported for different types of engineered AgNPs exposed to natural freshwater, synthetic seawater, and simulated estuarine waters. ${ }^{27,28}$ According to previous study, inorganic cations (such as $\mathrm{Ca}^{2+}$ and $\mathrm{Mg}^{2+}$ ) in environmental waters could induce the aggregation of AgNPs. $^{29}$

To eliminate the effects of inorganic ions on the photoreduction of AgNPs in environmental water, water from the Chaobai River was subjected to dialysis (1000 kDa molecular weight cutoffs) to remove most inorganic ions such as $\mathrm{Ca}^{2+}, \mathrm{Mg}^{2+}, \mathrm{Cl}^{-}$, and $\mathrm{SO}_{4}{ }^{2-}$ (Table S1) while retaining DOM content in the environmental water. Untreated and dialyzed river waters were compared for their ability to reduce $\mathrm{Ag}^{+}$(Figure 3). We observed that dialysis-treated water samples could reduce $\mathrm{Ag}^{+}$to smaller, yellow-colored AgNPs when compared to untreated water ( $80 \%$ hydrated diameter reduction). These combined results suggest that the removal of inorganic ions significantly inhibited the aggregation of AgNPs, and DOM in natural waters plays a major role in the reduction of $\mathrm{Ag}^{+}$.

Photoreduction of $\mathrm{Au}^{3+}$ to AuNPs in the Environmental Waters under Sunlight. On the basis of our experience with silver, we speculate that other metals that are easily reduced to their zerovalent state should exhibit similar photoreductive behaviors in environmental waters. To verify this, we extended our experiments to include $\mathrm{Au}^{3+}\left(\mathrm{AuCl}_{4}{ }^{-}\right)$and observed AuNP formation with the addition of $0.01 \mathrm{mmol} \mathrm{L}^{-1}$ of $\mathrm{AuCl}_{4}{ }^{-}$

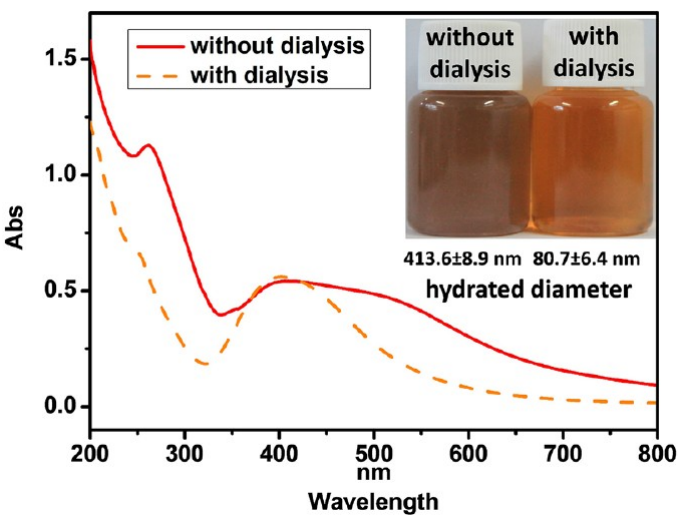

Figure 3. UV-vis spectrum of AgNPs formed in Chaobai River water with and without dialysis by spiking $1 \mathrm{mmol} \mathrm{L}^{-1}$ $\mathrm{AgClO}_{4}$ under sunlight. Note, after dialysis, the peak at $\sim 550 \mathrm{~nm}$ (stable agglomerates of AgNPs) disappeared, and the AgNP solution appeared yellow in color. Additionally, the hydrated diameter $(80.7 \mathrm{~nm})$ of AgNPs in the dialyzed river water is much smaller than that in the undialyzed river water $(413.6 \mathrm{~nm})$, suggesting that the aggregation of AgNPs was inhibited in the dialyzed river water.

(Figure 4). The formation of AuNPs was further confirmed by the comprehensive characterization of these nanoparticles formed with higher concentration of $\mathrm{AuCl}_{4}{ }^{-}\left(0.20 \mathrm{mmol} \mathrm{L}^{-1}\right)$ as a precursor (Figure 5 and Figures S4 and S5). The SAED patterns (Figure 5c,g) and lattice planes observed in HRTEM imaging (Figure $5 b, f$ ) can be indexed to fcc gold metal. Au(I) was also observed in the XPS (Figure S5), indicating the formation 

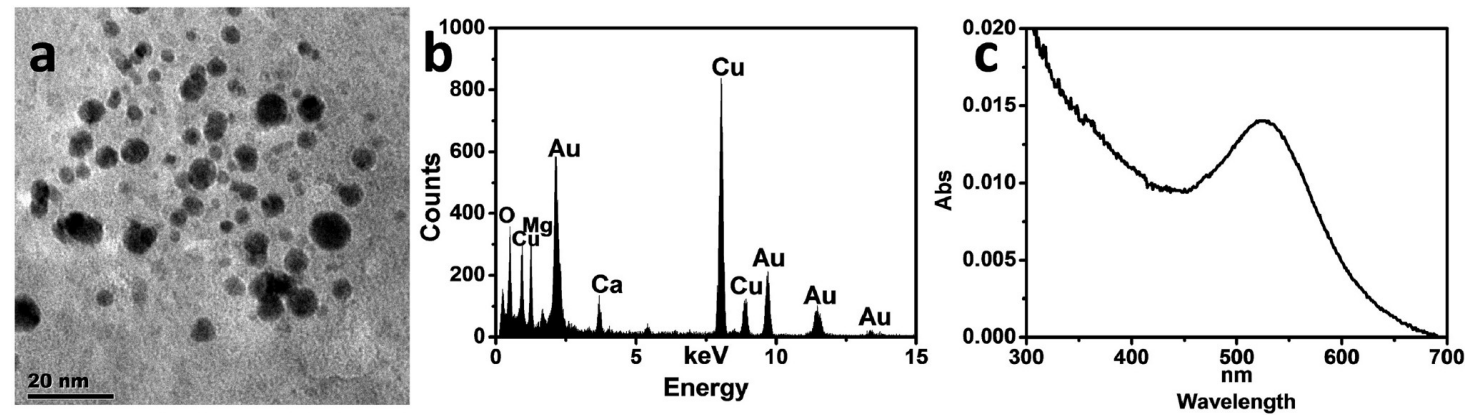

Figure 4. Identification of AuNPs produced by the reduction of $0.01 \mathrm{mmol} \mathrm{L}^{-1} \mathrm{AuCl}_{4}{ }^{-}$in Chaobai River water under sunlight. (a) TEM, (b) EDS, and (c) UV-vis spectrum of the formed AuNPs. The cumulative PAR is $10124.51 \mathrm{E} \mathrm{m}^{-2}$. Note, in (c), the background absorption of Chaobai River water was deducted from the prepared AuNPs solution.
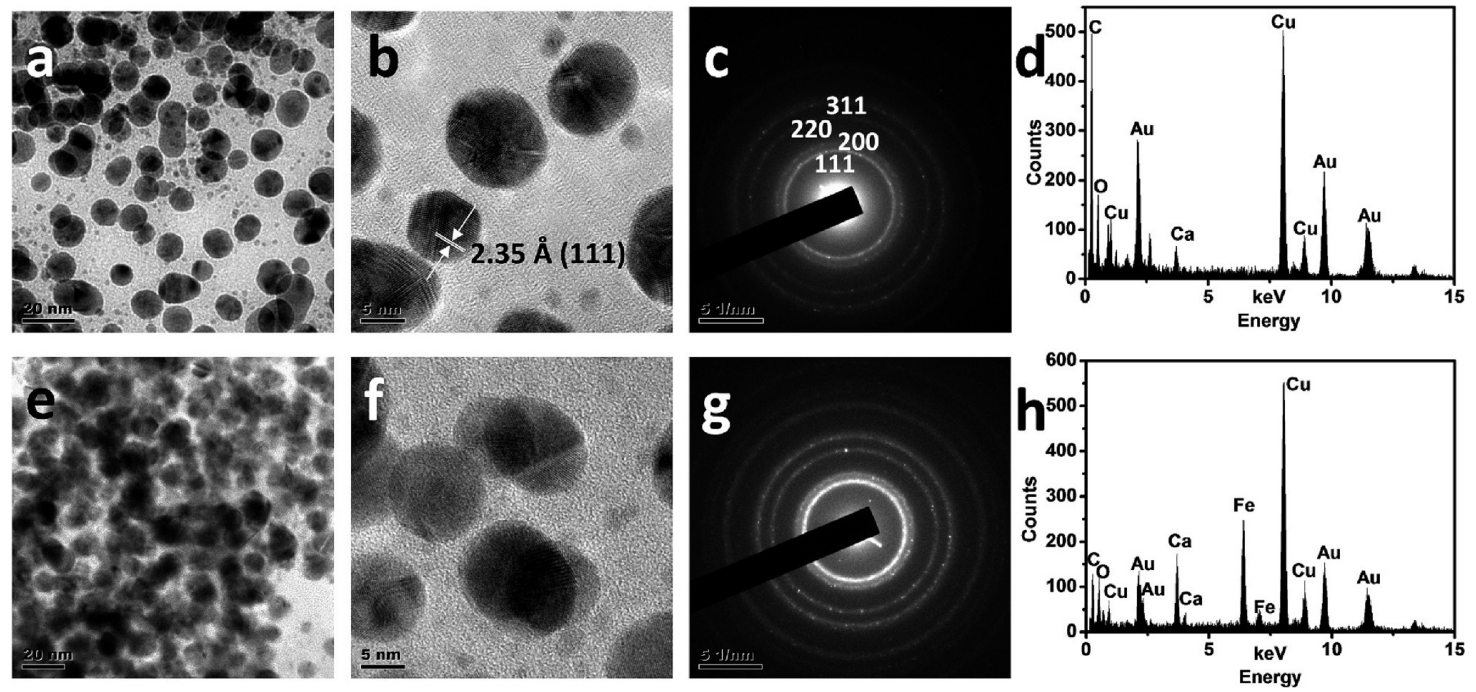

Figure 5. Identification of AuNPs produced by the reduction of $0.2 \mathrm{mmol} \mathrm{L}^{-1} \mathrm{Au}^{3+}$ in Chaobai River water. $(a, e) T E M,(b, f)$ HRTEM, (c,g) SAED, and (d,h) EDS of the formed AuNPs in upper solution (top a, b, c, and d), and precipitation (bottom e, f, g, h). The cumulative PAR is $13251.97 \mathrm{E} \mathrm{m}^{-2}$.

of AuNPs through intermediate $\mathrm{Au}(\mathrm{I})$ species. $^{30}$ Similar to AgNPs, long-time sunlight irradiation induced aggregation and sedimentation of AuNPs, and the $\mathrm{Au}$ in the sedimentation was confirmed to be elemental nanoparticles (Figure 5). These results provide additional evidence that the photoreduction by DOM is a potential source of metal nanoparticles in the environment.

Photoreduction of $\mathrm{Ag}^{+}$to AgNPs by DOM under Controlled Conditions. The kinetics of the reduction of $\mathrm{Ag}^{+}$to AgNPs were investigated using $\mathrm{HA}$ as a model for DOM under simulated sunlight. Various concentrations of $\mathrm{Ag}^{+}$, concentrations and origins of $\mathrm{HA}$, as well as irradiation times were studied comprehensively.

Under simulated sunlight, the solution turned to a pale yellow color with a UV-vis absorption peak around $400 \mathrm{~nm}$ (Figure S6a), which is the plasmon resonance of AgNPs. With time, the pale yellow color became increasingly yellow in color, and the corresponding plasmon resonance of AgNPs at $\sim 400 \mathrm{~nm}$ increased significantly. No color change and UV-vis absorption peak around $400 \mathrm{~nm}$ were observed for a
$\mathrm{Ag}^{+}-\mathrm{HA}$ solution under dark conditions or $\mathrm{Ag}^{+}$solution under simulated sunlight conditions, suggesting that both $\mathrm{HA}$ and simulated sunlight are important for AgNP formation.

Figure S6b,c in Supporting Information shows the effects of Aldrich $\mathrm{HA}$ and $\mathrm{Ag}^{+}$precursor concentrations on the absorbance of AgNPs with time, which characterizes the photoreduction of $\mathrm{AgClO}_{4}$ with $\mathrm{HA}$ relative to the initial concentration of both $\mathrm{HA}$ and $\mathrm{Ag}^{+}$ concentration. Results showed that the absorbance of AgNPs increased with $\mathrm{HA}$ and $\mathrm{Ag}^{+}$concentration. Moreover, the absorbance of AgNPs, indicating the concentration of AgNPs, ${ }^{31}$ increased almost linearly with irradiation time. The apparent kinetics of AgNP formation can be written as

$$
A=r \times t
$$

in which $A$ is the absorbance of AgNPs at $400 \mathrm{~nm}$, and $r$ is the formation rate of AgNPs.

Table S2 summarizes the $r$ values at different conditions, which linearly increased with increasing $\mathrm{HA}\left(0-10 \mathrm{mg} \mathrm{L}^{-1} \mathrm{DOC}\right)$ and $\mathrm{Ag}^{+}\left(0-1 \mathrm{mmol} \mathrm{L}^{-1}\right)$ 
concentration. Therefore, under simulated sunlight irradiation, the formation of AgNPs fits the pseudosecond-order reaction kinetics:

$$
r=k[\mathrm{HA}]\left[\mathrm{Ag}^{+}\right]
$$

which gives rise to $k=8.13 \times 10^{-4} \mathrm{~L}^{2} \cdot \mathrm{h}^{-1} \cdot(\mathrm{mg} \mathrm{DOC})^{-1}$. $\mathrm{mol}^{-1}$ or $9.20 \times 10^{-7} \mathrm{~L}^{2} \cdot \mathrm{E}^{-1} \mathrm{~m}^{2} \cdot(\mathrm{mg} \mathrm{DOC})^{-1} \cdot \mathrm{mol}^{-1}$. When the $\mathrm{HA}$ concentration was over $10 \mathrm{mg} \mathrm{L}^{-1}$, however, the increase of formation rate slowed down, indicating a kinetic shift to zero-order at higher HA concentration.

For quantification of formed AgNPs, dual-cloud point extraction was performed for selective extraction of produced AgNPs followed by microwave digestion/ inductively coupled plasma mass spectrometry (ICPMS) determination. ${ }^{32,33}$ It was found that for a solution containing $5 \mathrm{mg} \mathrm{L}^{-1}$ DOC of Aldrich $\mathrm{HA}$ and $1 \mathrm{mmol} \mathrm{L}^{-1}$ $\mathrm{AgClO}_{4}, 4.14 \%\left(4.47 \pm 0.30 \mathrm{mg} \mathrm{L}^{-1}\right)$ of the contained $\mathrm{Ag}^{+}$was transformed to AgNPs after $96 \mathrm{~h}$ simulated sunlight irradiation.

The $\mathrm{pH}$ dependence of AgNP formation was investigated to further elucidate the potential natural aquatic conditions and to probe possible formation mechanisms. Samples of HA from various origins, including two terrestrial $\mathrm{HA}$ samples (Aldrich $\mathrm{HA}$ and Acros $H A$ ) and one aquatic HA sample (SRHA), were compared for their ability to form AgNPs. The formation of AgNPs was found to be strongly dependent on $\mathrm{pH}$ for both Aldrich HA and SRHA. No AgNP formation was observed at lower $\mathrm{pH}$ ( $\mathrm{pH} 4.4$ and 5.2 for Aldrich $\mathrm{HA}$ and $\mathrm{pH} 6.2$ for SRHA), and the formation rate constant of AgNPs increased significantly with $\mathrm{pH}$ (Figure S6d and Table S2). In addition, at higher $\mathrm{pH}$ ( $\mathrm{pH} 6.7$ for Aldrich $\mathrm{HA}$ and $\mathrm{pH} 7.2$ for SRHA), even in dark conditions, pale yellow colored AgNPs were clearly observed with the corresponding UV-vis plasmon resonance peak, although its concentration was much lower than that under irradiation.

The $\mathrm{pH}$ dependence of the formation of AgNPs can be explained by the linear relationship between the redox potential of $\mathrm{HA}$ solution and $\mathrm{pH}$ (Figure S7). A lower redox potential at higher $\mathrm{pH}$ is ideal for AgNP formation.

The experiments revealed that all three sources of $\mathrm{HA}$ can reduce $\mathrm{Ag}^{+}$to AgNPs, but different kinetic characters were observed for Acros $\mathrm{HA}(\mathrm{pH}$ 6.2) and SRHA ( $\mathrm{pH}$ 6.4). For SRHA, the absorbance of AgNPs initially increased linearly and then leveled off, indicating a decrease in the growth rate of AgNPs. These phenomena suggested that, in this reaction, the reducing agent, $\mathrm{HA}$, is the limiting reagent. ${ }^{34}$ In addition, precipitation of AgNPs was observed with longer irradiation time, indicating the loss of the stability of AgNPs under irradiation. At higher $\mathrm{pH}$, both the reduction capacity and binding capability of HA increased, ${ }^{35}$ thus this absorbance-level-off phenomenon was not observed for SRHA at higher $\mathrm{pH}$ (pH 6.7 and 7.2).

Similarly, natural sunlight can also accelerate the reduction of $\mathrm{Ag}^{+}$to AgNPs in the presence of $\mathrm{HA}$ (Figures S8 and S9). No AgNPs were formed without $\mathrm{HA}$ even under sunlight irradiation. In dark conditions, the formation of a small amount of AgNPs was observed. With sunlight, the formation of AgNPs increased significantly. This result suggests that the reduction of silver ions is the combined result of $\mathrm{HA}$ and ambient sunlight. Given the higher intensity of natural sunlight than that of simulated sunlight, the formation rate of AgNPs under natural sunlight is expected to be much higher than that under simulated sunlight. For Aldrich HA (pH 6.2), Acros HA (pH 6.2), and SRHA ( $\mathrm{pH}$ 6.4), a linear relationship was observed between PAR and the absorbance of AgNPs. The formation rate of AgNPs relative to cumulative PAR is shown in Table S3. For SRHA (pH 6.7), a fast formation yellow AgNP was observed at the initial stage, which indicates that chemical reduction under dark condition is relatively important at higher $\mathrm{pH} .{ }^{13}$

Figure $\mathrm{S} 10$ shows the stability of the formed AgNPs at room temperature and $4{ }^{\circ} \mathrm{C}$, respectively. In the investigated period (30 days), no precipitation of AgNPs was observed. The UV-vis spectra revealed that both the plasmon resonance peak shape and intensity had no significant changes at $4{ }^{\circ} \mathrm{C}$. However, a slight increase of the plasmon resonance peak intensity was observed at RT, which should be ascribed to the further formation of AgNPs by HA reduction in the dark. ${ }^{13}$ These results suggest that photosynthesized AgNPs are very stable for a long period.

We found much faster formation of AgNPs in environmental water than in HA solution. Figure S7 and Table S1 show that the redox potentials in environmental water were much lower than that in $\mathrm{HA}$ solution. The difference of redox potentials between the environmental waters and HA solution may account for differences in formation kinetics of AgNPs.

Mechanism of the Photoreduction by DOM. The $\mathrm{pH}$ dependence of photoreduction indicates that the phenolic group of HA possibly plays an important role in the photoreduction of AgNPs. To verify this, original and phenolic group-blocked HA were compared for their ability to reduce $\mathrm{Ag}^{+}$under sunlight (as shown in Figure 6a). The photoreduction of $\mathrm{Ag}^{+}$to AgNPs was almost completely suppressed when the phenolic group-blocked Aldrich HA or SRHA was used, demonstrating that photoreduction should be ascribed to the phenolic group of HA.

The photoreduction of $\mathrm{Ag}^{+}$to AgNPs by the phenolic group of HA suggests that dissolved oxygen may contribute to this process by reacting with the phenolic group to produce superoxide anion free radical $\left(\mathrm{O}_{2}{ }^{--}\right)$, which reduces metal ions to low-valent metal. ${ }^{22,26,36}$ The photoinduced formation of $\mathrm{O}_{2}{ }^{--}$in SRHA solution 

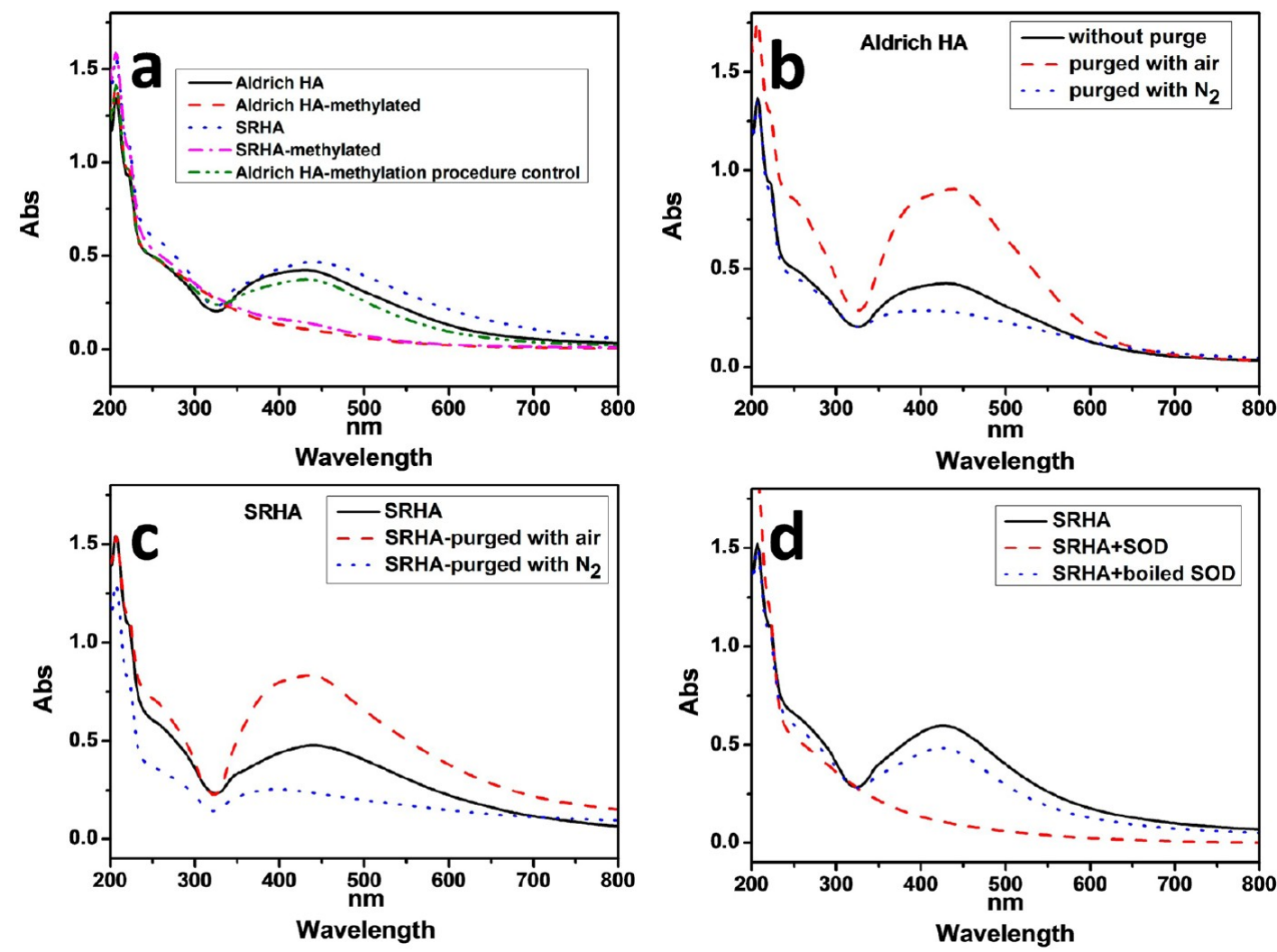

Figure 6. Characteristic absorbance spectrum of AgNPs produced by reduction of $1 \mathrm{mmol} \mathrm{L}^{-1} \mathrm{AgClO}_{4}$ under sunlight by DOM $\left(10 \mathrm{mg} \mathrm{C} \mathrm{mL}^{-1}\right)$. (a) Original HA and phenolic OH-blocked HA, (b,c) Aldrich HA and SRHA after purged with air and $\mathrm{N}_{2}$, (d) SRHA in the presence of $150 \mathrm{U} \mathrm{mL} \mathrm{LOD}^{-1}$. Note, in (d), the experiments were conducted after purged with air.

was first demonstrated by using a nitroblue tereazolium (NBT) method ${ }^{37,38}$ (Figure S11). To further elucidate the possible role of $\mathrm{O}_{2}{ }^{--}$in photoreduction, the effect of dissolved $\mathrm{O}_{2}$ on photoreduction of $\mathrm{Ag}$ was investigated (Figure $6 \mathrm{~b}, \mathrm{c}$ ). In the absence of oxygen, the photogeneration of AgNPs decreased significantly, and subsequently, when oxygen was reintroduced, the photogeneration of AgNPs significantly increased. This phenomenon indicated that $\mathrm{O}_{2}{ }^{--}$may play a decisive role in the photoreduction of $\mathrm{Ag}^{+}$.

The reduction of $\mathrm{Ag}^{+}$by $\mathrm{O}_{2}{ }^{--}$was further validated by the inhabitation of AgNP formation by superoxide dismutase (SOD) (Figure 6d). The presence of SOD was found to prevent the formation of AgNPs under natural sunlight, which clearly confirms that $\mathrm{O}_{2}{ }^{--}$is the key reductant in DOM-induced photoreduction.

\section{DISCUSSION}

Silver exists in the natural environment in various species, including $\mathrm{AgCl}, \mathrm{Ag}_{2} \mathrm{~S}$, freely dissolved $\mathrm{Ag}^{+}$, DOM-associated $\mathrm{Ag}^{+}$, as well as colloidal and particulate silver. The speciation of silver in aquatic system is controlled by $E_{\mathrm{h}}, \mathrm{pH}$, and organic or inorganic chelating ligands (such as $\mathrm{DOM}, \mathrm{S}^{2-}$, and $\mathrm{Cl}^{-}$). Theoretically, from a thermodynamic view, in a typical fresh water system $\left(1 \times 10^{-6} \mathrm{~mol} \mathrm{~L}^{-1}\right.$ of $\mathrm{Ag}^{+}, 1 \times 10^{-3} \mathrm{~mol} \mathrm{~L}^{-1}$ of $\mathrm{HS}^{-}, 0.03$ $\mathrm{mol} \mathrm{L}^{-1}$ of $\mathrm{CO}_{3}{ }^{2-}$, and $\left.0.01 \mathrm{~mol} \mathrm{~L}^{-1} \mathrm{Cl}^{-}\right), \mathrm{Ag}^{0}$ is one of the main possible $\mathrm{Ag}$ phases besides $\mathrm{AgCl}$ and $\mathrm{Ag}_{2} \mathrm{~S}$. ${ }^{39}$
Although naturally elemental $\mathrm{Ag}\left(\mathrm{Ag}^{\circ}\right)$ and even AgNPs have been observed in ore deposits, ${ }^{40}$ the formation of naturally occurring AgNPs in the aquatic environment has not been well understood.

Our comprehensive characterization (UV-vis, TEM, SAED, EDS, and XRD) of AgNPs provides conclusive evidence for the formation of AgNPs in environmental waters. As demonstrated by previous study, ${ }^{41,42}$ free or organic binding $\mathrm{Ag}^{+}$is widely present in a fresh water environment. This fraction of Ag could possibly be reduced to AgNPs. Additionally, $\mathrm{AgCl}$ was also observed in the solution (Figure 2e), which also can be transformed into AgNPs under irradiation, as demonstrated by the early photographic industry. ${ }^{43}$

DOM was demonstrated to be the main reductant for reduction of $\mathrm{Ag}^{+}$in environmental water by a dialysis experiment. The relationship between formation of AgNPs, UV-vis, and the fluorescence spectrum of DOM in environmental water (Table S1) also strongly suggests that the photoactive chromophoric DOM is the key reductant. The formation mechanism of AgNPs was further elucidated by using $\mathrm{HA}$ as a model for DOM. The $\mathrm{pH}$-dependent formation rates indicated that the HA phenolic group plays an important role in the reduction. As the photoreduction of $\mathrm{Ag}^{+}$to AgNPs was almost completely suppressed when the phenolic group of HA was blocked by methylation, we conclude that photoreduction is related to the 
phenolic group of HA. Phenolic-group-mediated photoreduction of the metal ion could proceed by the following two possible pathways: (1) direct charge transfer from the phenolic group to the metal ion in the phenol-metal ion complex; ${ }^{20,21}$ (2) dissolved oxygen reacts with the phenolic group to produce superoxide anion free radical $\left(\mathrm{O}_{2}{ }^{-}\right)$, which reduces metal ions to low-valent metal. ${ }^{22,26,36}$ We further found that dissolved $\mathrm{O}_{2}$ significantly increased the reductive formation of AgNPs, indicating that $\mathrm{O}_{2}{ }^{--}$plays a decisive role in the photoreduction of $\mathrm{Ag}^{+}$, possibly by the following reaction: ${ }^{21,44}$

$$
\begin{gathered}
\mathrm{HA}_{\mathrm{red}}+\mathrm{O}_{2}+h v \rightarrow \mathrm{HA}_{\mathrm{ox}}+\mathrm{O}_{2}^{\cdot-} \\
\mathrm{O}_{2}^{\cdot-}+\mathrm{Ag}^{+} \rightarrow \mathrm{Ag}^{0}+\mathrm{O}_{2} \\
\mathrm{Ag}^{0}+\mathrm{O}_{2}^{\cdot-} \rightarrow \mathrm{Ag}^{0-}+\mathrm{O}_{2} \\
\mathrm{Ag}^{0-}+\mathrm{Ag}^{+} \rightarrow \mathrm{Ag}^{0}+\mathrm{Ag}^{0}
\end{gathered}
$$

$\mathrm{O}_{2}{ }^{--}$has been demonstrated to be an effective reducing agent for $\mathrm{Ag}^{+}$to form AgNPs. ${ }^{44}$ The generation of $\mathrm{O}_{2}{ }^{--}$can also be significantly enhanced through close proximity to AgNPs, ${ }^{45}$ which can, in turn, further enhance the generation and growth of AgNPs. The reduction of $\mathrm{Ag}^{+}$by $\mathrm{O}_{2}^{\cdot-}$ was validated by the inhabitation of AgNP formation by SOD (Figure 6), which can catalyze $\mathrm{O}_{2}{ }^{\cdot-}$ into $\mathrm{O}_{2}$ and $\mathrm{H}_{2} \mathrm{O}_{2} \cdot{ }^{44}$ As reductive $\mathrm{O}_{2}{ }^{\cdot-}$ can be depleted by SOD and the resulting $\mathrm{O}_{2}{ }^{46,47}$ and $\mathrm{H}_{2} \mathrm{O}_{2}{ }^{48}$ can dissolute AgNPs to $\mathrm{Ag}^{+}$, the formation of AgNPs should be inhibited in the presence of SOD. We found that SOD can significantly prevent the formation of AgNPs under natural sunlight. Slight decreases in AgNP formation by boiled SOD was also observed, which could be attributed to the complexation of $\mathrm{Ag}^{+}$ by the denatured protein, ${ }^{49}$ thus decreasing the concentration of free $\mathrm{Ag}^{+}$. Nevertheless, these results clearly confirm that $\mathrm{O}_{2}{ }^{--}$is the key reductant in the DOM-mediated photoreduction.

Under sunlight, various environmental waters and varying representative DOM samples, including terrestrial (Aldrich $\mathrm{HA}$ and Acros HA) and aquatic HA (SRHA), can reduce $\mathrm{Ag}^{+}$to $A g N P s$, indicating that this reduction process is general for DOM in the natural environment. The formation of AgNPs fits the pseudosecond-order reaction kinetics, indicating that the concentrations of both $\mathrm{HA}$ and $\mathrm{Ag}^{+}$in environmental water play major roles in influencing AgNP formation. The $\mathrm{pH}$-dependent reduction suggests that alkaline aqueous environments are favorable for the reduction of $\mathrm{Ag}^{+}$by DOM. As in this process, besides as a reductant, ${ }^{13}$ DOM functions also as a coating agent to stabilize AgNPs through steric and charge interaction, ${ }^{13,50}$ and the formed AgNPs are very stable over months in dark conditions. This stabilizing effect of DOM can improve the migration of AgNPs with water flow over long distances. On the other hand, long-time sunlight irradiation could induce the aggregation and sedimentation of AgNPs, possibly owning to dipole-dipole interaction between particles, ${ }^{51}$ which would lead to eliminating these AgNPs from water to sediment.

Our new evidence that sunlight-induced reduction of ionic $\mathrm{Ag}$ and $\mathrm{Au}$ to their metallic nanoparticles by DOM in environmental waters suggests that this chemical reduction process may be general for other metals with high reduction potential. These results enrich our knowledge about not only the environmental transformation of EMNPs but also the possible natural source of AgNPs and AuNPs in the aquatic environment.

Typically, AgNPs are believed to be nonpersistent in realistic aquatic compartments containing dissolved oxygen due to the oxidative dissolution of AgNPs to Ag ions. ${ }^{46,47,52}$ However, findings in our study indicate that dissolved oxygen can transform to $\mathrm{O}_{2}{ }^{--}$in sunlit DOMrich water and induce the re-formation of AgNPs from dissolved $\mathrm{Ag}^{+}$, which increases the persistence and transport of AgNPs. In addition, photoreduction of the dissoluted $\mathrm{Ag}^{+}$from AgNPs may decrease the concentration of $\mathrm{Ag}^{+}$, which possibly influences the toxicity of AgNPs to an organism. ${ }^{53,54}$ These effects should be taken into account when assessing the environmental fates and toxicity of engineered AgNPs.

This study also sheds light on the naturally occurring metal nanoparticles in the environment. In the Ag or $\mathrm{Au}$ ion-rich environments, such as ore tailing and wastewaters from electronic industry, the formation of AgNPs or AuNPs from ionic species through the photoreduction procedure is highly possible. Besides biogenic pathway, ${ }^{55}$ the photogeneration of nanomaterials from dissolved metals could be a possible source of naturally occurring AgNPs or AuNPs, which provides further evidence of the difficulty of differentiating between natural and engineered nanoparticles. Moreover, the photogeneration of AuNPs and AgNPs might explain the wide occurrence of AuNPs and AgNPs in gold and silver deposits, ${ }^{17,56,57}$ which possibly plays an important role in the biogeochemical cycle of $\mathrm{Ag}$ and Au. ${ }^{16}$ In the deposition process, AuNPs and AgNPs could be initially formed through photoreduction by DOM, and further solar irradiation could induce the precipitation of these nanoparticles. ${ }^{51}$ The precipitation and adsorption of AuNPs and AgNPs on minerals and rocks (such as sulfide minerals and carbonaceous rocks) could consequently result in the supergene enrichment of $\mathrm{Au}$ and $\mathrm{Ag}{ }^{58}$

Considering the toxicity and possible bioaccumulation of nanoparticles in marine and terrestrial food chains, ${ }^{9-11}$ the formation of AgNPs and AuNPs by natural chemical process is of particular interest to further elucidate the toxicity and bioaccumulation of $\mathrm{Ag}$ and $\mathrm{Au}$ in the natural environment. Additionally, although organism-mediated reduction of $\mathrm{Au}^{59}$ and 
$\mathrm{Ag}^{60}$ is widely observed in the lab or environmental conditions, the exact mechanism of this bioreduction is still unknown. Given that bacterial production of superoxide may be a driving force in $\mathrm{Mn}$ (II) oxidation, ${ }^{61}$ superoxide-driven reduction is another reasonable cause for the organism-mediated formation of nanoparticles of $\mathrm{Au}^{0}$ and $\mathrm{Ag}^{0}$ in the environment.

\section{CONCLUSIONS}

In conclusion, we have observed that the DOM in natural water can reduce $\mathrm{Ag}^{+}$and $\mathrm{AuCl}_{4}{ }^{-}$to their elemental nanoparticles under sunlight. By using $\mathrm{HA}$ as a model for DOM, we found that the formation of AgNPs was highly dependent on $\mathrm{pH}$ and the concentration of $\mathrm{Ag}^{+}$and DOM. We have identified that the reduction was mediated by superoxide from photoirradiation of the phenol group in DOM, and dissolved $\mathrm{O}_{2}$ significantly enhanced the formation of AgNPs. This process is a possible source of naturally occurring AgNPs and AuNPs in the environment and also possibly critical in the supergene enrichment of $\mathrm{Ag}$ and $\mathrm{Au}$. This study could also sheds light on the transformation, fates, and effects of AgNPs and AuNPs in the aquatic environment.

\section{MATERIALS AND METHODS}

Chemicals and Instrumentation. Silver nitrate, silver perchlorate, and chloroauric acid (with $>99.0 \%$ purity) were purchased from Beijing Chemicals (Beijing, China). Suwannee River humic acid (SRHA), from an aquatic source, was purchased from the International Humic Substances Society (IHSS, St. Paul, MN). Terrestrial-origin humic acid sodium salts from Acros Organics (Morris Plains, NJ) and Sigma-Aldrich (St. Louis, MO) were used as obtained. The dissolved organic carbon, DOC, of HA solution was determined with a Phoenix 8000 UV-persulfate total organic carbon analyzer (Tekmar-Dohrmann, Cincinnati, $\mathrm{OH}$ ). Superoxide dismutase (SOD) was obtained from bovine erythrocytes (Sigma-Aldrich, St. Louis, MO). All pH measurements were performed on an ORION 4 STAR pH - ISE benchtop (Thermo Fisher Scientific, Waltham, MA). The redox potential of the HA solution was also determined on an ORION 4 STAR pH.ISE benchtop (Thermo Fisher Scientific, Waltham, MA) with a 9678 BNWP combination redox/ORP electrode (Beverly, MA). Before each measurement, the electrode was calibrated by ORP standard solution (Orion 96796).

Sampling and Characterization of Environmental Waters. Environmental water samples, including spring water, lake water, and river water, were collected from Beijing by using gloved hands to fill precleaned $2 \mathrm{~L}$ Teflon bottles. The samples were kept in a cooler and transported to the laboratory immediately. All of the water samples were filtered through a $0.2 \mu \mathrm{m}$ glass fiber filter. The inorganic ions, dissolved organic carbon, redox potential, UV-visible and fluorescence spectrum were determined before photochemical experiment (Table S1).

Formation of AgNPs and AuNPs under Simulated Sunlight. Experiments were performed employing a solar simulator (Beijing Lighting Research Institute, Beijing) equipped with a waterrefrigerated $500 \mathrm{~W}$ Xe source lamp. A $200 \mathrm{~mL}$ sample was added into a $250 \mathrm{~mL}$ glass beaker and covered with Pyrex glass slide (1 $\mathrm{mm}$ thickness). The incident simulated sunlight was perpendicular with the glass slide. The intensity of the simulated sunlight was measured as $221 \mu \mathrm{mol} \mathrm{m} \mathrm{m}^{-2} \mathrm{~s}^{-1}$ using a LI-192 Quantum Sensor (LICOR Biosciences, Lincoln, NE). During the simulated sunlight exposure, the reaction temperature was maintained at $\sim 20{ }^{\circ} \mathrm{C}$ by an internal exhaust fan. The $\mathrm{pH}$ of the solutions was measured prior to and after the irradiation, and no significant changes were noted ( $\Delta \mathrm{pH}<0.5$ units).

Formation of AgNPs and AuNPs under Natural Sunlight. The experiments were performed in $500 \mathrm{~mL}$ FEP (fluorinated ethylene propylene) bottles (Nalgene, Rochester, NY). In each batch of experiments, dark control experiment was performed in FEP Teflon bottles wrapped by three layers of aluminum foil and then one layer of black plastic bags to maintain similar temperature with the sunlight-exposed counterpart. During the experiments, intensity of ambient photosynthetically active radiation and temperature were measured at $15 \mathrm{~min}$ intervals routinely using a LI-192 Quantum Sensor and HMP50 Air Temperature Probe (LICOR Biosciences, Lincoln, NE).

Other experimental details and characterization for AgNPs and AuNPs are given in Supporting Information.
Conflict of Interest: The authors declare no competing financial interest.

Acknowledgment. We thank Dr. Y. Shen in the Beijing National Center for Electron Microscopy for TEM characterizations, and Dr. A. Chuang from Michigan State University for her valuable suggestions on the paper. The authors would also like to express their sincere thanks to the anonymous reviewers for their valuable comments and suggestions on the paper. This work was supported by the National Science Fund for Distinguished Young Scholars (21025729), the National Basic Research Program of China (2010CB933502), and the National Natural Science Foundation of China (20977101, 20921063).

Supporting Information Available: Experimental details and additional results. This material is available free of charge via the Internet at http://pubs.acs.org.

\section{REFERENCES AND NOTES}

1. Kamat, P. V. Photophysical, Photochemical and Photocatalytic Aspects of Metal Nanoparticles. J. Phys. Chem. B 2002, 106, 7729-7744.

2. Nowack, B.; Krug, H. F.; Height, M. 120 Years of Nanosilver History: Implications for Policy Makers. Environ. Sci. Technol. 2011, 45, 1177-1183.

3. Mueller, N. C.; Nowack, B. Exposure Modeling of Engineered Nanoparticles in the Environment. Environ. Sci. Technol. 2008, 42, 4447-4453.

4. Benn, T. M.; Westerhoff, P. Nanoparticle Silver Released into Water from Commercially Available Sock Fabrics. Environ. Sci. Technol. 2008, 42, 4133-4139.

5. Benn, T.; Cavanagh, B.; Hristovski, K.; Posner, J. D.; Westerhoff, P. The Release of Nanosilver from Consumer Products Used in the Home. J. Environ. Qual. 2010, 39, 1875-1882.

6. Kaegi, R.; Sinnet, B.; Zuleeg, S.; Hagendorfer, H.; Mueller, E.; Vonbank, R.; Boller, M.; Burkhardt, M. Release of Silver Nanoparticles from Outdoor Facades. Environ. Pollut. 2010, 158, 2900-2905.

7. Geranio, L.; Heuberger, M.; Nowack, B. The Behavior of Silver Nanotextiles during Washing. Environ. Sci. Technol. 2009, 43, 8113-8118.

8. Lewinski, N.; Colvin, V.; Drezek, R. Cytotoxicity of Nanoparticles. Small 2008, 4, 26-49.

9. Ferry, J. L.; Craig, P.; Hexel, C.; Sisco, P.; Frey, R.; Pennington, P. L.; Fulton, M. H.; Scott, I. G.; Decho, A. W.; Kashiwada, S.; et al. Transfer of Gold Nanoparticles from the Water Column to the Estuarine Food Web. Nat. Nanotechnol. 2009, 4, 441-444.

10. Judy, J. D.; Unrine, J. M.; Bertsch, P. M. Evidence for Biomagnification of Gold Nanoparticles within a Terrestrial Food Chain. Environ. Sci. Technol. 2011, 45, 776-781.

11. Croteau, M.-N. L.; Misra, S. K.; Luoma, S. N.; Valsami-Jones, E. Silver Bioaccumulation Dynamics in a Freshwater Invertebrate 
after Aqueous and Dietary Exposures to Nanosized and lonic Ag. Environ. Sci. Technol. 2011, 45, 6600-6607.

12. Glover, R. D.; Miller, J. M.; Hutchison, J. E. Generation of Metal Nanoparticles from Silver and Copper Objects: Nanoparticle Dynamics on Surfaces and Potential Sources of Nanoparticles in the Environment. ACS Nano 2011, 5, 8950-8957.

13. Akaighe, N.; MacCuspie, R. I.; Navarro, D. A.; Aga, D. S.; Banerjee, S.; Sohn, M.; Sharma, V. K. Humic Acid-Induced Silver Nanoparticle Formation under Environmentally Relevant Conditions. Environ. Sci. Technol. 2011, 45, 38953901.

14. Anderson, C. W. N.; Brooks, R. R.; Stewart, R. B.; Simcock, R. Harvesting a Crop of Gold in Plants. Nature 1998, 395, 553554.

15. Weber, F.-A.; Voegelin, A.; Kaegi, R.; Kretzschmar, R. Contaminant Mobilization by Metallic Copper and Metal Sulphide Colloids in Flooded Soil. Nat. Geosci. 2009, 2, 267-271.

16. Hough, R. M.; Noble, R. R. P.; Reich, M. Natural Gold Nanoparticles. Ore Geol. Rev. 2011, 42, 55-61.

17. Arturo Gomez-Caballero, J.; Guadalupe Villasenor-Cabral, M.; Santiago-Jacinto, P.; Ponce-Abad, F. Hypogene Ba-Rich Todorokite and Associated Nanomeric Native Silver in the San Miguel Tenango Mining Area, Zacatlan, Puebla, Mexico. Can. Mineral. 2010, 48, 1237-1253.

18. Hough, R. M.; Noble, R. R. F.; Hitchen, G. J.; Hart, R.; Reddy, S. M.; Saunders, M.; Clode, P.; Vaughan, D.; Lowe, J.; Gray, D. J.; et al. Naturally Occurring Gold Nanoparticles and Nanoplates. Geology 2008, 36, 571-574.

19. Large, R. R.; Bull, S. W.; Maslennikov, V. V. A Carbonaceous Sedimentary Source-Rock Model for Carlin-Type and Orogenic Gold Deposits. Econ. Geol. 2011, 106, 331-358.

20. Fujii, M.; Rose, A. L.; Waite, T. D.; Omura, T. Oxygen and Superoxide-Mediated Redox Kinetics of Iron Complexed by Humic Substances in Coastal Seawater. Environ. Sci. Technol. 2010, 44, 9337-9342.

21. Voelker, B. M.; Morel, F. M. M.; Sulzberger, B. Iron Redox Cycling in Surface Waters: Effects of Humic Substances and Light. Environ. Sci. Technol. 1997, 31, 1004-1011.

22. Rose, A. L.; Waite, T. D. Reduction of Organically Complexed Ferric Iron by Superoxide in a Simulated Natural Water. Environ. Sci. Technol. 2005, 39, 2645-2650.

23. Costa, M.; Liss, P. S. Photoreduction of Mercury in Sea Water and Its Possible Implications for $\mathrm{Hg}^{\circ}$ Air-Sea Fluxes. Mar. Chem. 1999, 68, 87-95.

24. Fukushima, M.; Tatsumi, K. Light Acceleration of Iron(III) Reduction by Humic Acid in the Aqueous Solution. Colloids Surf., A 1999, 155, 249-258.

25. Spokes, L. J.; Liss, P. S. Photochemically Induced Redox Reactions in Seawater. 1. Cations. Mar. Chem. 1995, 49, 201-213.

26. Gaberell, M.; Chin, Y. P.; Hug, S. J.; Sulzberger, B. Role of Dissolved Organic Matter Composition on the Photoreduction of $\mathrm{Cr}(\mathrm{VI})$ to $\mathrm{Cr}(\mathrm{III})$ in the Presence of Iron. Environ. Sci. Technol. 2003, 37, 4403-4409.

27. Chinnapongse, S. L.; MacCuspie, R. I.; Hackley, V. A. Persistence of Singly Dispersed Silver Nanoparticles in Natural Freshwaters, Synthetic Seawater, and Simulated Estuarine Waters. Sci. Total Environ. 2011, 409, 2443-2450.

28. Piccapietra, F.; Sigg, L.; Behra, R. Colloidal Stability of Carbonate-Coated Silver Nanoparticles in Synthetic and Natural Freshwater. Environ. Sci. Technol. 2012, 46, 818825.

29. Mukherjee, B.; Weaver, J. W. Aggregation and Charge Behavior of Metallic and Nonmetallic Nanoparticles in the Presence of Competing Similarly-Charged Inorganic Ions. Environ. Sci. Technol. 2010, 44, 3332-3338.

30. Das, S. K.; Liang, J.; Schmidt, M.; Laffir, F.; Marsili, E. Biomineralization Mechanism of Gold by Zygomycete Fungi Rhizopous oryzae. ACS Nano 2012, 10.1021/ nn301502s.

31. Harada, M.; Katagiri, E. Mechanism of Silver Particle Formation during Photoreduction Using In Situ Time-Resolved SAXS Analysis. Langmuir 2010, 26, 17896-17905.
32. Liu, J. F.; Chao, J. B.; Liu, R.; Tan, Z. Q.; Yin, Y. G.; Wu, Y.; Jiang, G. B. Cloud Point Extraction as an Advantageous Preconcentration Approach for Analysis of Trace Silver Nanoparticles in Environmental Waters. Anal. Chem. 2009, 81, 6496-6502.

33. Chao, J. B.; Liu, J. F.; Yu, S. J.; Feng, Y.D.; Tan, Z. Q.; Liu, R.; Yin, Y. G. Speciation Analysis of Silver Nanoparticles and Silver Ions in Antibacterial Products and Environmental Waters via Cloud Point Extraction-Based Separation. Anal. Chem. 2011, 83, 6875-6882.

34. Eustis, S.; Krylova, G.; Eremenko, A.; Smirnova, N.; Schill, A. W.; El-Sayed, M. Growth and Fragmentation of Silver Nanoparticles in Their Synthesis with a FS Laser and CW Light by Photo-Sensitization with Benzophenone. Photochem. Photobiol. Sci. 2005, 4, 154-159.

35. Sachs, S.; Bernhard, G. Humic Acid Model Substances with Pronounced Redox Functionality for the Study of Environmentally Relevant Interaction Processes of Metal lons in the Presence of Humic Acid. Geoderma 2011, 162, 132140.

36. Rose, A. L.; Waite, D. Role of Superoxide in the Photochemical Reduction of Iron in Seawater. Geochim. Cosmochim. Acta 2006, 70, 3869-3882.

37. Yamakoshi, Y.; Umezawa, N.; Ryu, A.; Arakane, K.; Miyata, N.; Goda, Y.; Masumizu, T.; Nagano, T. Active Oxygen Species Generated from Photoexcited Fullerene (C60) as Potential Medicines: $\mathrm{O}_{2}{ }^{-}$. versus ${ }^{1} \mathrm{O}_{2}$. J. Am. Chem. Soc. 2003, 125 , 12803-12809.

38. Zhan, M. Determination of Photochemically-Generated Reactive Oxygen Species in Natural Water. J. Environ. Sci. 2009, 21, 303-306.

39. Levard, C.; Hotze, E. M.; Lowry, G. V.; Brown, G. E. Environmental Transformations of Silver Nanoparticles: Impact on Stability and Toxicity. Environ. Sci. Technol. 2012, 46, 69006914.

40. Reich, M.; Chryssoulis, S. L.; Deditius, A.; Palacios, C.; Zuniga, A.; Weldt, M.; Alvear, M. "Invisible" Silver and Gold in Supergene Digenite $\left(\mathrm{Cu}_{1.8} \mathrm{~s}\right)$. Geochim. Cosmochim. Acta 2010, 74, 6157-6173.

41. Wen, L.-S.; Santschi, P. H.; Gill, G. A.; Paternostro, C. L.; Lehman, R. D. Colloidal and Particulate Silver in River and Estuarine Waters of Texas. Environ. Sci. Technol. 1997, 31, 723-731.

42. Gill, G. A.; Wen, L. S.; Lehman, R.; Tang, D. G.; Santschi, P. Silver in Colorado Watersheds. In The 5th International Conference Proceedings: Transport, Fate and Effects of Silver in the Environment; Andren, A. W., Bober, T. W. B., Eds.; Madison, WI, Sep 28-Oct 1, 1997; pp 155-162.

43. Wang, G.; Nishio, T.; Sato, M.; Ishikawa, A.; Nambara, K.; Nagakawa, K.; Matsuo, Y.; Niikura, K.; ljiro, K. Inspiration from Chemical Photography: Accelerated Photoconversion of $\mathrm{AgCl}$ to Functional Silver Nanoparticles Mediated by DNA. Chem. Commun. 2011, 47, 9426-9428.

44. Jones, A. M.; Garg, S.; He, D.; Pham, A. N.; Waite, T. D. Superoxide-Mediated Formation and Charging of Silver Nanoparticles. Environ. Sci. Technol. 2011, 45, 1428-1434.

45. Zhang, Y.; Aslan, K.; Previte, M. J. R.; Geddes, C. D. MetalEnhanced Superoxide Generation: A Consequence of Plasmon-Enhanced Triplet Yields. Appl. Phys. Lett. 2007, 91, 023114.

46. Liu, J. Y.; Sonshine, D. A.; Shervani, S.; Hurt, R. H. Controlled Release of Biologically Active Silver from Nanosilver Surfaces. ACS Nano 2010, 4, 6903-6913.

47. Liu, J. Y.; Hurt, R. H. Ion Release Kinetics and Particle Persistence in Aqueous Nano-Silver Colloids. Environ. Sci. Technol. 2010, 44, 2169-2175.

48. Chatterjee, A.; Santra, M.; Won, N.; Kim, S.; Kim, J. K.; Bin Kim, S.; Ahn, K. H. Selective Fluorogenic and Chromogenic Probe for Detection of Silver lons and Silver Nanoparticles in Aqueous Media. J. Am. Chem. Soc. 2009, 131, 20402041.

49. Rezaei Behbehani, G.; Saboury, A.; Taherkhani, A.; Barzegar, L.; Mollaagazade, A. A Thermodynamic Study on the Binding of Mercury and Silver lons to Urease. J. Therm. Anal. Calorim. 2011, 105, 1081-1086. 
50. Cumberland, S. A.; Lead, J. R. Particle Size Distributions of Silver Nanoparticles at Environmentally Relevant Conditions. J. Chromatogr., A 2009, 1216, 9099-9105.

51. Cheng, Y. W.; Yin, L. Y.; Lin, S. H.; Wiesner, M.; Bernhardt, E.; Liu, J. Toxicity Reduction of Polymer-Stabilized Silver Nanoparticles by Sunlight. J. Phys. Chem. C 2011, 115, 4425-4432.

52. Zhang, W.; Yao, Y.; Sullivan, N.; Chen, Y. Modeling the Primary Size Effects of Citrate-Coated Silver Nanoparticles on Their lon Release Kinetics. Environ. Sci. Technol. 2011, $45,4422-4428$.

53. Kittler, S.; Greulich, C.; Diendorf, J.; Koeller, M.; Epple, M. Toxicity of Silver Nanoparticles Increases during Storage Because of Slow Dissolution under Release of Silver lons. Chem. Mater. 2010, 22, 4548-4554.

54. Yang, X.; Gondikas, A.; Marinakos, S. M.; Auffan, M.; Liu, J.; Hsu-Kim, H.; Meyer, J. The Mechanism of Silver Nanoparticle Toxicity Is Dependent on Dissolved Silver and Surface Coating in Caenorhabditis elegans. Environ. Sci. Technol. 2012, 46, 1119-1127.

55. Narayanan, K. B.; Sakthivel, N. Biological Synthesis of Metal Nanoparticles by Microbes. Adv. Colloid Interface Sci. 2010, $156,1-13$.

56. Palenik, C. S.; Utsunomiya, S.; Reich, M.; Kesler, S. E.; Wang, L. M.; Ewing, R. C. "Invisible" Gold Revealed: Direct Imaging of Gold Nanoparticles in a Carlin-Type Deposit. Am. Mineral. 2004, 89, 1359-1366.

57. Zhu, X. Q.; Wang, Z. G. Advances in Geochemical Research on Nanometer Materials. Prog. Nat. Sci. 2006, 16, 331-337.

58. Zhu, X. Q.; Zhang, Z. G.; Jiang, Z. C. Genesis of Carlin-Type Gold Deposits in Southwestern Guizhou Province, China. Chin. Sci. Bull. 1999, 44, 466-469.

59. Reith, F.; Fairbrother, L.; Nolze, G.; Wilhelmi, O.; Clode, P. L.; Gregg, A.; Parsons, J. E.; Wakelin, S. A.; Pring, A.; Hough, R.; et al. Nanoparticle Factories: Biofilms Hold the Key to Gold Dispersion and Nugget Formation. Geology 2010, 38, 843846.

60. Ahmad, A.; Mukherjee, P.; Senapati, S.; Mandal, D.; Khan, M. I.; Kumar, R.; Sastry, M. Extracellular Biosynthesis of Silver Nanoparticles Using the Fungus Fusarium oxysporum. Colloids Surf., B 2003, 28, 313-318.

61. Learman, D. R.; Voelker, B. M.; Vazquez-Rodriguez, A. I.; Hansel, C. M. Formation of Manganese Oxides by Bacterially Generated Superoxide. Nat. Geosci. 2011, 4, 95-98. 